\title{
Kinetics and Specificities of the T Helper-Cell Response to GP120 in the Asymptomatic Stage of HIV-1 Infection
}

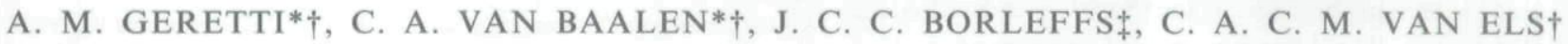 \\ \& A. D. M. E. OSTERHAUS*† \\ *Department of Virology, Erasmus University, Rotterdam, The Netherlands \\ $\uparrow$ Laboratory of Immunobiology, National Institute of Public Health and Environmental Protection, Bilthoven, The Netherlands \\ $\ddagger$ Department of Internal Medicine, Utrecht Academic Hospital, Utrecht, The Netherlands
}

Geretti AM, Van Baalen CA, Borleffs JCC, van Els CACM, Osterhaus ADME. Kinetics and Specificities of the T Helper-Cell Response to gp120 in the Asymptomatic Stage of HIV-1 Infection. Scand J Immunol 1994;39:355-62

Peripheral blood mononuclear cells from 36 asymptomatic HIV-1 seropositive individuals were tested longitudinally for in vitro T-cell proliferation and IL-2 production in response to synthetic peptides spanning the entire gp 120 of HIV-1. At baseline, significant T-cell proliferation to pooled and individual peptides was observed in 15 of the 36 donors. After 12 months, proliferative responses to peptide pools were lost or decreased significantly in most donors. Responses appeared to fluctuate over time: at 12 months new recognition sites were detected in four of 10 donors showing $\mathrm{T}$-cell proliferation at baseline, as well as in five of 15 donors with no previous proliferative responses. IL-2 production appeared to be a more sensitive and longer preserved parameter of T-helper cell function: at baseline the majority of donors with no T-cell proliferation produced IL- 2 in response to pooled peptides. This response was not decreased significantly after 12 months. The overall patterns of response to both pooled and individual peptides were heterogeneous among donors. Multiple recognition sites were detected in both variable and conserved regions of gp120, but no pool or individual peptide was recognized by all responders. Functional T-cell responses were not statistically correlated to $\mathrm{CD}^{+}{ }^{+}$cell percentile and absolute numbers.

Professor Dr A. D. M. E. Osterhaus, Department of Virology, Erasmus University Rotterdam, P.O. Box 1738, 3000 DR Rotterdam, The Netherlands

\section{INTRODUCTION}

T-helper lymphocytes are known to play a central role in the generation of protective immunity against infectious agents [1-4]. Although the immune mechanisms which may mediate protection against HIV-1 are still largely unclear, increasing evidence suggests that the generation of strong $\mathrm{T}$ helper-cell responses is critical to the prevention or control of HIV-1 infection. T helper-cell responses against gp120 have been demonstrated in individuals exposed repeatedly to HIV-1 but lacking serological or other evidence of HIV-1 infection [5]. Furthermore, HIV-1 infected apes, which do not seem to develop HIV-1-related disease, have vigorous $\mathrm{T}$ helper-cell responses towards various HIV-1 antigens $[6,7]$.

Among HIV-1 antigens, the envelope protein is believed to play a major role in the induction of protective B- and T-cell mediated immunity against the virus [8-10]. The T helper-cell immunostimulatory properties of gp 120 have been studied in animal models, vaccinated volunteers, and in both seroposit- ive and seronegative donors $[9,11-21]$. Synthetic peptides have been commonly used for the screening of the gp120specific $\mathrm{T}$ helper-cell repertoire. Beside providing information on defined T helper-cell epitopes, the use of discrete peptides rather than whole antigens has been reported to increase the detection level of specific responses [18, 21, 22], and to allow discrimination between putative T-cell activating and suppressive sites [22, 23]. Moreover, this approach circumvents the problem of HIV-1 induced defects of antigen presentation which may interfere with the in vitro analysis of $\mathrm{T}$ helper-cell responses [24,25]. Although measurement of peripheral blood mononuclear cell (PBMC) proliferation upon antigen stimulation is widely used to test $\mathrm{T}$ helper-cell reactivity in vitro, it has been suggested recently that the measurement of IL-2 production is a more sensitive parameter to test for exposure to HIV-1 than T-cell proliferation $[5,15]$.

The authors measured T-cell proliferation and IL-2 production of PBMC from 36 asymptomatic HIV-1 infected individuals in response to in vitro stimulation with synthetic 
peptides spanning the entire gp 120 of HIV-1IIIB. T helper-cell responses against several conserved and variable sites of gp 120 in HIV-1 infected individuals have been described previously. However, since most previous studies have focused on limited numbers of recognition sites $[11,15,16,19,20]$, to the authors' knowledge the $\mathrm{T}$ helper-cell repertoire for the entire protein has not been screened before in seropositive individuals. Although T helper-cell responses observed in asymptomatic HIV-1 infected individuals have been higher than in those who have progressed to symptomatic disease [16, 18, 19], little is known about the longevity of these responses during the asymptomatic phase of infection. The authors' goal was to gain further insight into the specificities and kinetics of $\mathrm{T}$ helper-cell responses during the asymptomatic stage of HIV-1 infection, before severe $\mathrm{CD}^{+}{ }^{+}$cell-count depletion and deterioration of the clinical status occur. The results indicate that the recognition of gp 120 is heterogeneous in asymptomatic seropositive individuals and appears to fluctuate over time. Furthermore, the authors showed that in HIV-1-infected individuals IL-2 production is a more sensitive and, longer preserved parameter of $\mathrm{T}$ helper-cell function than proliferative T-cell responses.

\section{MATERIALS AND METHODS}

Study group. The study included 36 HIV-1 infected individuals 24 males and 12 females), aged 22-52 years, randomly selected from a cohort monitored by the Utrecht University Hospital (Utrecht, The Netherlands) between 1987 and 1991 . HIV-1 infection was related to high-risk homosexual or bisexual contacts $(n=21)$, heterosexual contacts $(n=10)$, or intravenous drug use $(n=5)$. To be included in the study, HIV-1-infected individuals had to have baseline circulating $\mathrm{CD}^{+}{ }^{+}$cell counts above 400 cells $/ \mu \mathrm{l}$, and, throughout the study, had to show no symptoms or signs of HIV-1 related disease (stage II of the Centre for Disease Control (CDC), Atlanta, GA, USA, classification). $\mathrm{T}$ helper-cell responses were evaluated retrospectively with PBMC collected at a baseline visit and, depending on availability of blood samples, 6 and 12 months later. Responses were assessed in nine separate experiments, each including five HIV-1 infected donors. Nine of the 36 donors were tested twice in independent experiments. Total leucocyte counts, as well as percentages and absolute numbers of $\mathrm{CD}^{+}$cells, were determined by standard methods. PBMC from 11 HIV-seronegative healthy blood donors were used as controls.

Synthetic peptides. A panel of 45 partially overlapping synthetic peptides ( 20 mers overlapping by 10 amino acids), spanning the entire sequence of gp 120 of the IIIB strain of HIV-1, was provided by Dr H. Holmes through the Medical Research Council's AIDS Directed Programme (South Mimms, Potters Bar, UK). Individual peptides or nine pools (A-I) of five contiguous peptides were used for in vitro stimulation of PBMC.

Stimulation of PBMC. PBMC were separated from heparinized blood by density gradient centrifugation on Ficoll-Hypaque (Nycomed Pharma AS, Oslo, Norway), washed three times in RPMI 1640 containing penicillin $(100 \mathrm{U} / \mathrm{ml})$, streptomycin $(100 \mu \mathrm{g} / \mathrm{ml}), 10^{-5}$ м $\beta$-mercapto ethanol and $2 \mathrm{~mm} \mathrm{L-glutamine} \mathrm{(referred} \mathrm{to} \mathrm{as} \mathrm{'complete}$ medium'), and cryopreserved in liquid nitrogen until use. Cell viability (as assessed by trypan blue exclusion) was preserved after thawing. PBMC $\left(1.5 \times 10^{5} /\right.$ well) were cultured in triplicate in flat bottomed 96-well microtitre plates (Greiner, Frickenhausen, Ger- many) in a final volume of $150 \mu \mathrm{l}$ of complete medium supplemented with $10 \%$ heat inactivated human serum pooled from seronegative donors. Cells were stimulated with either pooled or individual peptides, at a final concentration of $10 \mu \mathrm{g} / \mathrm{ml}$ of each peptide. Phytohaemoagglutinin (PHA-M, Boehringer Mannheim, Mannheim, Germany) at a final concentration of $10 \mu \mathrm{g} / \mathrm{ml}$, was used to test lymphocyte responsiveness to non-specific stimulation. Unstimulated cultures (cells in medium supplemented with $10 \%$ human serum) were used as medium control.

$T$ helper-cell assays. For T-cell proliferation, PBMC were incubated for 6 days at $37^{\circ} \mathrm{C}$ in a $5 \% \mathrm{CO}_{2}$ humidified atmosphere, pulsed for $18 \mathrm{~h}$ with $0.5 \mu \mathrm{Ci}$ of $\left({ }^{3} \mathrm{H}\right)$-thymidine, and harvested on glass-fibre filter papers. $\left({ }^{3} \mathrm{H}\right)$-thymidine incorporation was measured in a liquid scintillation $\beta$-spectrometer. For measurement of IL-2 production, PBMC were cultured as outlined above in the presence of an anti-IL-2 receptor monoclonal antibody $(\mathrm{MoAb})$ (kindly provided by $\mathrm{Dr} \mathrm{L}$. Aarden, CLB, Amsterdam, The Netherlands), at 1:500 final dilution, to prevent IL-2 consumption [15]. Supernatants were harvested 7 days later and frozen at $-20^{\circ} \mathrm{C}$ until use. IL-2 level was defined as the ability to stimulate the proliferation of the IL-2-dependent cell line CTLL-2. For this purpose, 2 days after the last feeding, CTLL cells $\left(0.5 \times 10^{4}\right.$ cells/well $)$ were cultured in round bottomed 96 -well microtitre plates, in complete medium supplemented with $10 \%$ heat inactivated fetal calf serum (FCS). Supernatants from PBMC cultures were added to the wells at $50 \mu \mathrm{l} /$ well (dilution 1:2). Following a 24 -h incubation at $37^{\circ} \mathrm{C}$, CTLL proliferation was determined by measuring overnight incorporation of $\left({ }^{3} \mathrm{H}\right)$-thymidine, as described above. CTLL cells were maintained in $25-\mathrm{cm}^{2}$ flasks (Becton Dickinson, UK) in $10 \mathrm{ml}$ of complete medium supplemented with $10 \%$ FCS and $10 \mathrm{U} / \mathrm{ml}$ recombinant IL-2 (rIL-2, Biotest Diagnostics, Dreieich, Germany).

Results of PBMC and CTLL proliferation assays are given as stimulation indices (SI) according to the following formula:

$$
\mathrm{SI}=\frac{\text { mean counts per } \min \text { in stimulated cultures }}{\text { mean counts per min in medium control cultures }}
$$

Standard error of mean values was consistently below $27 \%$.

Statistical analysis. Proliferative responses and IL-2 production measurements with PBMC from 11 HIV-1 seronegative blood donors showed a (one-sided) $99 \%$ upper confidence limit from the tdistribution of 2.87 and 2.98 , respectively. Based on this observation, SI from HIV-1 seropositive donors were considered significant when scoring $\geqslant 3.0$. Linear regression analysis was performed to evaluate the relationship between $\mathrm{T}$ helper-cell responses and absolute numbers and percentages of circulating $\mathrm{CD}^{+}{ }^{+}$cells.

\section{RESULTS}

\section{Proliferative responses to gp120 peptide pools at baseline}

Baseline proliferative responses of PBMC from 36 HIV-1 seropositive donors stimulated in vitro with nine pools (A-I) of five contiguous peptides are shown in Table 1 (left panel). Significant T-cell proliferation to at least one peptide pool was detected in 15 of the 36 donors $(42 \%$; referred to as 'responders'), whereas 21 donors (referred to as 'non-responders') did not show significant proliferative responses. The mean number of pools recognized by all responders was $2.9 \pm 1.1$. Ten of the 15 responders recognized three or more pools. Positive SI values ranged up to 14.3 (mean $5.1 \pm 2.7$ ). 
Table 1. Proliferative responses of PBMC from HIV-1 seropositive donors to peptide pools A to I. (bold: SI $\geqslant 3.0$ ).

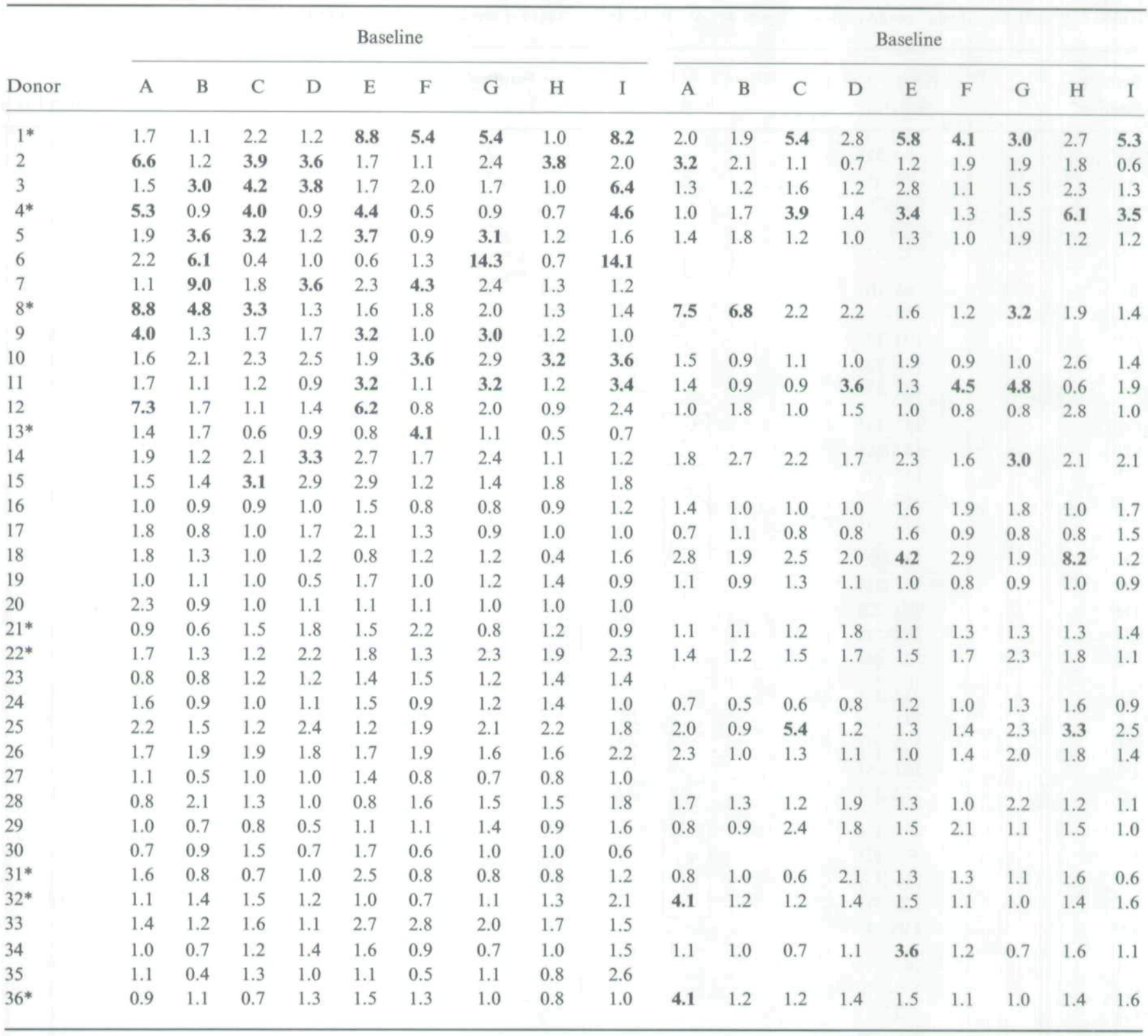

* Results are mean SI values from two independent experiments (SD $<10 \%)$.

PBMC from 11 HIV-1 seronegative healthy controls did not proliferate to any of the peptide pools (data not shown).

\section{Proliferative responses to gp120 peptide pools 12 months after baseline}

Proliferative responses could be evaluated 12 months after baseline determination with PBMC from 10 responders and 15 non-responders. As shown in Table 1 (right panel), four of the 10 responders lost their proliferative responses (individuals $3,5,10$ and 12), whereas six retained their responses to at least one pool of peptides. Although in most cases proliferative responses were directed towards the same pools recognized at baseline, new responses to previously unrecog- nized pools were demonstrated in four responders (individuals $4,8,11$ and 14). New reactivities were observed also with PBMC from five of the 15 non-responders towards one (individuals 32, 34 and 36) or two (individuals 18 and 25) peptide pools. The mean number of pools recognized by all donors was $2.2 \pm 1.4$. Positive SI values ranged up to 8.2 (mean

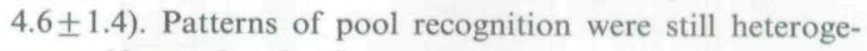
neous 12 months after baseline.

The overall response of the PBMC from these 25 donors to non-specific stimulation with PHA remained intact during these 12 months. Differences in peptide pool-specific responses did not correlate with differences in PHA-induced responses: 18 of the donors showed a higher SI to PHA at 12 
Table 2. Proliferative responses to individual peptides of PBMC from 15 HIV-1 seropositive donors responding to one or more peptide pools.

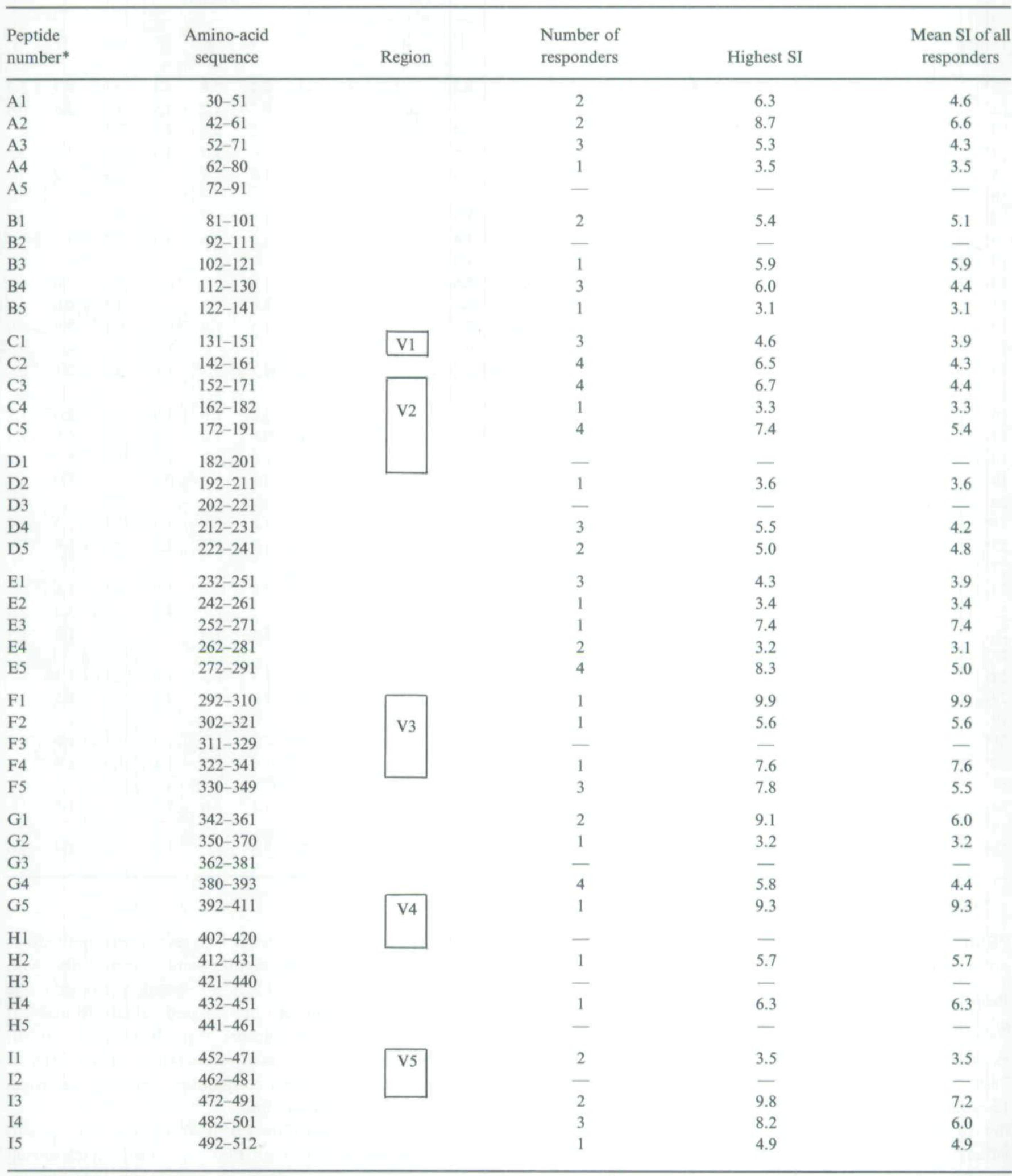

* Individual peptides are indicated by respective pool (A-I) and by position inside the pool (1-5). 


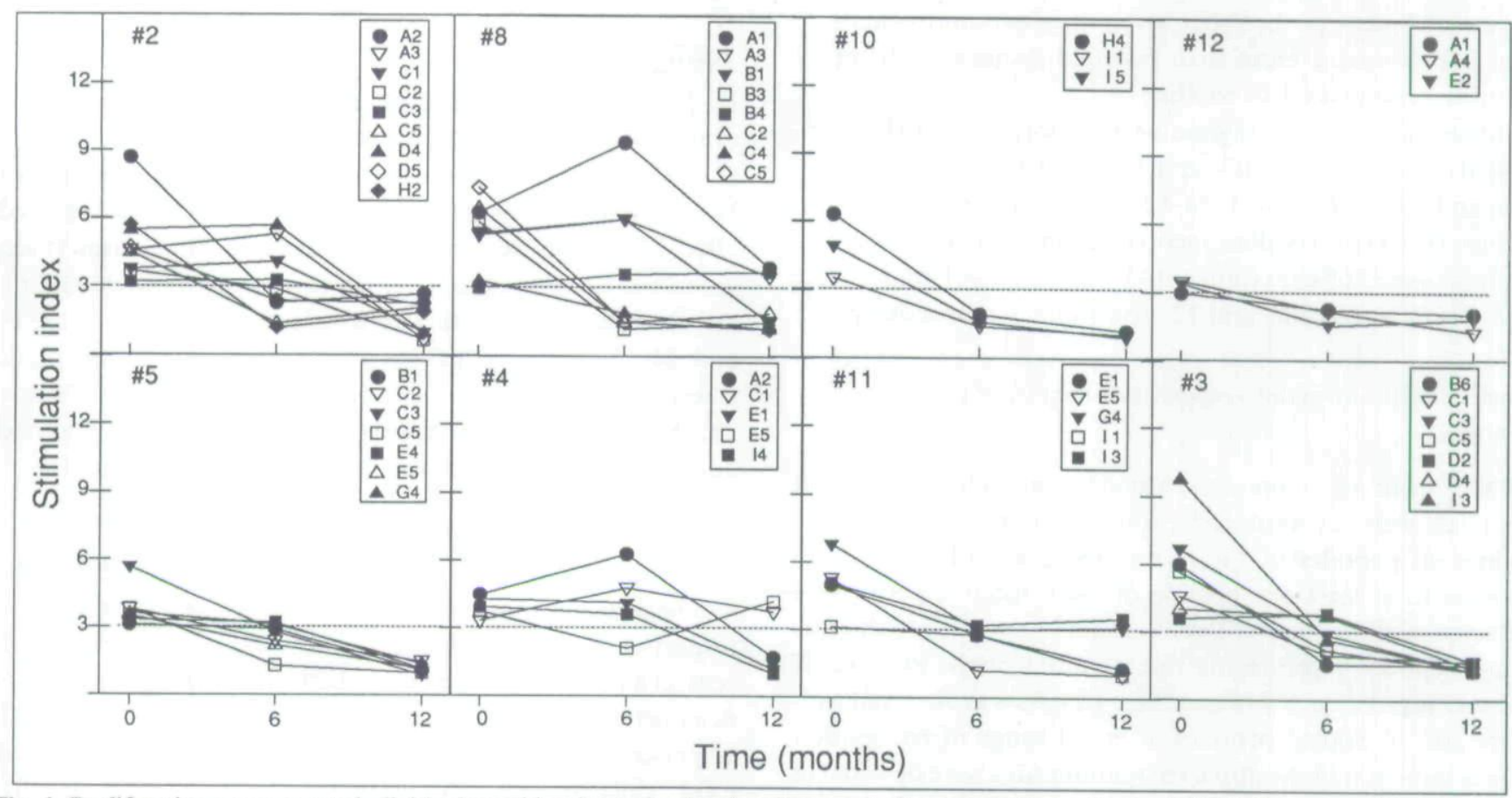

Fig. 1. Proliferative responses to individual peptides determined at baseline, and after 6 and 12 months in eight HIV-1 seropositive individuals. Symbols indicate individual peptides used for cell stimulation.

Table 3. IL-2 production defined as SI of CTLL proliferation to culture supernatants of PBMC from HIV-1 seropositive donors stimulated with peptide pools $\mathrm{A}-\mathrm{I}$. (bold: $\mathrm{SI} \geqslant 3.0$ )

Baseline

12 months

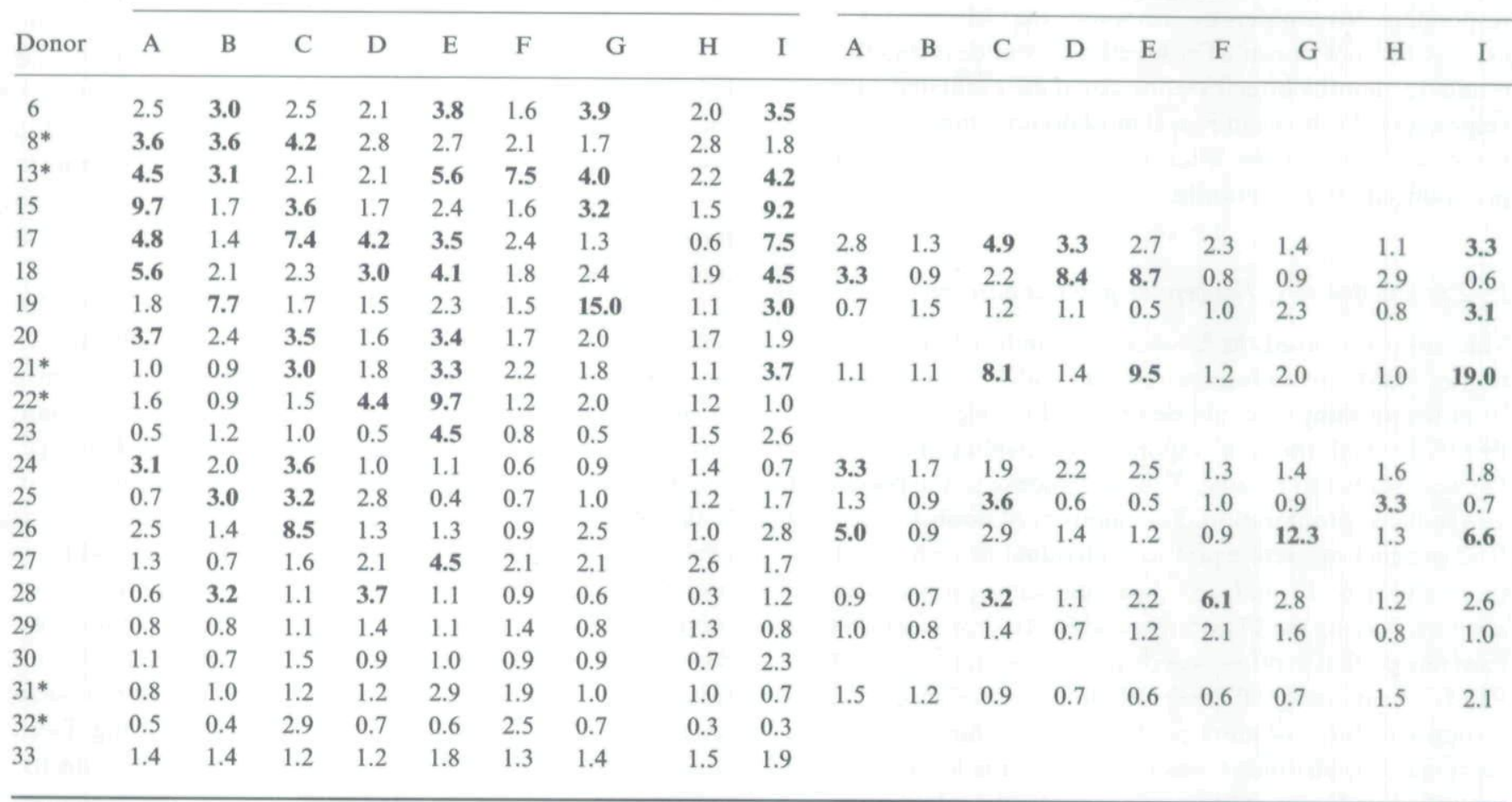

\footnotetext{
* Results are mean SI values of CTLL proliferation to culture supernatants obtained from two independent experiments (SD $<10 \%$ ).
} 
months whereas of the other seven only two (individuals 12 and 34) showed a more than two-fold decrease in SI at 12 months as compared to baseline.

Mean values of $\left({ }^{3} \mathrm{H}\right)$-thymidine incorporation in PHA-stimulated cultures were $16,064 \mathrm{cpm}$ (range: $4508-32,208$ ) at baseline and 19,583 (range: 4374-67,073) 12 months later. Mean values of $\left({ }^{3} \mathrm{H}\right)$-thymidine incorporation in medium control cultures were $665 \mathrm{cpm}$ (range: 143-1690) and $461 \mathrm{cpm}$ (range: $138-1155)$, at baseline and 12 months later, respectively.

\section{Kinetics of proliferative responses to individual gp 120 peptides}

PBMC from 15 seropositive donors responding to pooled peptides were assayed for proliferative responses to the individual peptides of the recognized pools (Table 2). Responses to at least one peptide of the respective pools were detected in all 15 donors. Twelve donors responded to three or more peptides representing one or more pools. Positive SI values ranged up to 9.9 (mean $5.1 \pm 1.1$ ). As was observed with responses to pooled peptides, a broad range of recognition was demonstrated. Multiple recognition sites were detected in both variable and conserved regions of gp120, but no single peptide was able to stimulate PBMC from all responders. Five peptides covering amino-acid sequences 142-161, 152-171, 172-191, 272-291, and 380-393, and designated C2, C3, C5, $\mathrm{E} 5$, and G4, respectively, induced responses more frequently. Nine of the 15 responders $(67 \%)$ recognized at least one of these peptides (data not shown). As a control, proliferative responses to the individual peptides of non-recognized pools were measured with PBMC from six responders and four nonresponders. No proliferative responses were observed in these assays (data not shown). The kinetics of peptide recognition at 6 and 12 months after baseline could be evaluated in eight responders. As shown in Fig. 1, most donors showed a general decrease in reactivity after 6 months, which was more pronounced after 12 months.

\section{$I L-2$ production to gp120 peptide pools at baseline}

The authors assayed the baseline pool-induced IL-2 production of PBMC from four responders and 17 non-responders from whom samples could be obtained (Table 3, left panel). PBMC from all the four responders (individuals 6, 8, 13 and 15) were shown to produce IL-2 in response to the pools that also induced proliferation. The numbers of pools stimulating IL-2 production were equal to (individual 8) or higher than (individuals 6, 13 and 15) those inducing proliferative responses. Among the 17 non-responders, IL-2 production to at least one pool of peptides was demonstrated in 12 cases $(71 \%)$. PBMC from nine of these 12 donors produced IL-2 in response to three or more pools. The mean number of pools recognized by all donors was $2.9 \pm 1.4$. In the healthy control group, stimulation with pooled peptides did not induce significant IL-2 production (data not shown).

\section{IL-2 production to gp120 peptide pools 12 months after baseline}

IL-2 production in response to pooled peptides could be evaluated 12 months after baseline determination in 10 donors (Table 3, right panel). Among eight donors who had shown IL-2 responses at baseline, the number of pools recognized after 12 months remained unchanged in three cases (individuals 21, 25 and 28), increased in one case (individual 26), and decreased in the other four cases (individuals 17, 18, 19 and 24). New reactivities to previously unrecognized pools emerged in three of the eight donors (individuals 25, 26 and 28). No new reactivities emerged in the two donors who had failed to produce IL-2 at baseline (individuals 29 and 31).

\section{$T$ helper-cell responses in relation to circulating $\mathrm{CD}^{+}$cells}

Absolute numbers and percentages of circulating $\mathrm{CD}^{+}$cells had baseline mean values of $786 \pm 291$ cells $/ \mu$ l and $36 \pm 9.5 \%$, respectively. After 12 months, mean values were $656 \pm 262$ cells $/ \mu \mathrm{l}$ and $30 \pm 10 \%$, respectively. Linear regression analysis demonstrated the absence of significant association between $\mathrm{T}$ helper-cell responses and absolute or percentile numbers of $\mathrm{CD}^{+}{ }^{+}$cells, at baseline or 12 months later (data not shown). Moreover, baseline CD4 ${ }^{+}$cell parameters proved not to be predictive for loss of T-helper responses 12 months later.

\section{DISCUSSION}

In this paper the authors have shown that $\mathrm{T}$-cell proliferative responses to partially overlapping synthetic peptides covering the entire amino-acid sequence of gp120 are heterogeneous in asymptomatic HIV-1 infected individuals and decline significantly during a 12-month observation period. As compared to T-cell proliferation, measurement of IL-2 production upon specific stimulation appears to be a more informative and longer preserved parameter of $\mathrm{T}$ helper-cell function (Table 3 ). This is in line with earlier observations by Clerici et al. [5], suggesting that IL-2 production by $\mathrm{T}$ cells in response to synthetic peptides is a more sensitive indicator of exposure to HIV-1 than the presence of serum antibody, T-cell proliferation, or PCR assessment.

Proliferative responses obtained with individual peptides were concordant with those obtained with pools of five contiguous peptides. This allowed the authors to economize on the use of PBMC in in vitro assays. The patterns of response towards both pooled and individual peptides were heterogeneous among donors, and multiple sites were recognized in both variable and conserved regions of gp120 (Table 2). This is likely to reflect, at least in part, $\mathrm{MHC}$ polymorphism which is probably high in this group of individuals who were selected randomly from a large panel of asymptomatic seropositive donors with $\mathrm{CD}^{+}{ }^{+}$counts above 400 . A similar heterogeneous response to synthetic peptides covering the entire amino-acid sequence of SIV gp120 was observed recently using T-cell clones from immunized macaques [26]. In HIV-1 infected individuals, most previous studies on $\mathrm{T}$ helper-cell responses to gp120 synthetic peptides have focused on limited numbers 
of recognition sites $[11,15,16,19,20]$, often predicted as immunodominant $\mathrm{T}$ helper-cell epitopes on the basis of their amphipathic $\alpha$-helic structure [27]. However, in a comprehensive analysis of the COOH-terminal of gp120 Wahren et al. [18] showed that, $\mathbf{T}$ helper-cell responses can be elicited not only by peptides with the predicted $\alpha$-helical structure, but e.g. also by peptides with a $\beta$-turn configuration. Our data showed the presence of $\mathrm{T}$-helper determinants scattered throughout gp120 (Table 2). Comparison of these results with those obtained in earlier reports is complicated by the fact that in many cases lower SI threshold values have been considered positive. The authors chose to consider positive, values above 3.0, on the basis of results obtained with PBMC from 11 seronegative donors, whose SI-value t-distribution showed a $99 \%$ upper confidence limit of 2.87 for proliferative responses, and 2.98 for IL-2 production. It is noteworthy that proliferation to the $\mathrm{T}$ helper-cell epitope envT2 (amino acids 112-124) described previously [28] was observed in three of the 15 responders, whereas none of the donors showed T-cell proliferation to the other two T-helper epitopes envT1 (amino acids 428-443) [29] and p18 (amino acids 315-319) [30] (Table 2). In the study described here none of the pooled or individual peptides were recognized by all or most responding donors and, consequently, no immunodominant site could be identified. The authors were able to map five recognition sites to amino-acid sequences 142-161 (peptide C2), 152-171 (peptide C3), 172-191 (peptide C5), 272-291 (peptide E5), and 380-393 (peptide G4), which induced blastogenic responses with higher frequency: nine of the 15 responding donors $(67 \%)$ proliferated to at least one of these five peptides (Table 2). One possible explanation for the lack of detectable $\mathrm{T}$ helper-cell responses in some of the individuals studied, could be the use of synthetic peptides spanning the IIIB sequence of gp120 in donors infected with HIV-1 strains of different geographical origin. This approach was chosen intentionally to obtain information on the recognition of gp120 determinants whose immunostimulatory properties are conserved among different viral strains and may therefore have particular relevance to vaccine development.

Results of earlier studies indicate that individuals in the advanced stage of HIV-1 infection have weaker antigenspecific $\mathrm{T}$ helper-cell responses than asymptomatic individuals $[16,18,19]$. Moreover, a sequential loss of $\mathrm{T}$ helper-cell reactivity, to recall first antigens and then alloantigens and mitogens, has been described in HIV-1 infected individuals by Clerici et al. [31]. The authors' goal in the study described here was to evaluate the kinetics of the gp120-specific T-helper responses in the early phase of infection, before severe depletion of $\mathrm{CD}_{4}^{+}$cell and development of HIV-1-related disease occured. One interesting aspect in the longitudinal evaluation of both T-cell proliferation and IL-2 production to pooled peptides was the emergence, after 12 months, of new reactivities not detected at baseline, which in several cases compensated for the loss of determinants recognized previously (Tables 1 and 3). A fluctuation of gp120-specific T helper-cell responses over time was suggested also by the kinetics of responses to individual peptides. In three of the eight donors studied (individuals 2, 4 and 11), proliferative responses to individual peptides were lost after 6 or 12 months, whereas those to the respective pools were still detectable. Although the identification of the new sites of recognition might have brought interesting information, lack of cell samples prevented further investigation.

In the authors' study $\mathrm{T}$ helper-cell functional responses were shown not to be correlated to absolute or percentual numbers of circulating $\mathrm{CD}^{+}$cells, both at baseline and 12 months later. Moreover, baseline $\mathrm{CD}^{+}{ }^{+}$cell parameters were not found to be predictive for the persistence or loss of $\mathrm{T}$ helper-cell responsiveness 12 months later. This is not surprising in view of earlier observations that the $T$ helper-cell functionality of seropositive individuals is affected very early in the course of HIV-1 infection and may be predictive for the onset of decline in $\mathrm{CD}^{+}$cell numbers, rather than a consequence of such decline [31-35].

The authors' cohort of 36 seropositive individuals remained asymptomatic throughout the study. Subsequent clinical follow-up showed that all donors remained asymptomatic up to 24 months after the baseline visit. The only exception was individual 24, who showed no specific proliferative responses and low levels of $\mathrm{IL}-2$ production both at baseline and 12 months later, and has in the meantime progressed to symptomatic disease (CDCIV-C1).

Collectively, the authors' results suggest that a progressive deterioration of HIV-1-specific T helper-cell function occurs during the early stage of HIV-1 infection. The antigen-specific T-cell proliferation declines first, whereas the ability to produce IL-2 upon specific stimulation is preserved for longer. This tendency towards progressive decline appears to develop with a fluctuating pattern, so that the loss of reactivities is compensated initially for by the emergence of newly acquired recognition sites. Further prospective evaluation of the cohort studied, may reveal a possible relationship between the gp 120specific T helper-cell function and progression of HIV-1related disease.

\section{ACKNOWLEDGMENTS}

The authors would like to express gratitude to Dr O. Klepper from the National Institute of Public Health and Environmental Protection for assistance in statistical analyses, and to F.I. Wijnhold from the Utrecht Academical Hospital for technical assistance. They would also like to thank C. Kruyssen for help in preparing the manuscript. This work has been supported by a grant from the Health Research Council (grant no. 91-027), The Hague, The Netherlands.

\section{REFERENCES}

1 Russel SM, Liew FY. Cell cooperation in antibody responses to influenza virus I. Priming of helper T cells by internal components of the virion. Eur J Immunol 1980;10:791-6.

2 Murray K, Bruce SA, Hinnen A et al. Hepatitis B virus antigens made in microbial cells immunise against viral infection. EMBO 1984;3:645-50. 
3 Larson HL, Feng MF, Horohov DW, Moore RN, Rouse BT. Role of T-lymphocytes subsets in recovery from herpes simplex virus infection. J Virol 1984;50:56-9.

4 Greenberg PD, Kern DE, Cheever MA. Therapy of disseminated murine leukemia with cyclophosphamide and immune Lyt$1+, 2 \mathrm{~T}$ cells. Tumor eradication does not require participation of cytotoxic T cells. J Exp Med 1985;161:1122-34.

5 Clerici M, Giorgi JV, Chou C et al. Cell-mediated response to human immunodeficiency virus (HIV) Type 1 in seronegative homosexual men with recent sexual exposure to HIV-1. J Infect Dis 1992;165:1012-19.

6 Eichberg JW, Zarling JM, Alter $\mathrm{HJ}$ et al. T-cell responses to human immunodeficiency virus (HIV) and its recombinant antigens in HIV-infected chimpanzees. J Virol 1987;61:3804-8.

7 Krohn K, Ranki A, Lusso P et al. Proliferative T-cell response to HIV envelope glycoprotein in immunized and infected primates and human beings. J Med Primatol 1989;18:363-9.

8 Mills KH, Nixon GDF, McMichael AJ. T-cell strategies in AIDS vaccines: MHC-restricted T cell responses to HIV proteins. AIDS 1989;3:101-10.

9 Zagury D, Bernard J, Cheynier R et al. A group-specific anamnestic immune reaction against HIV-1 induced by a candidate vaccine against AIDS. Nature 1988;332:728-31.

10 Berman P, Gregory T, Riddle L et al. Protection of chimpanzees from infection by HIV-1 after vaccination with recombinant glycoprotein gp120 but not gp160. Nature 1990;345:622-5.

11 Berzofsky JA, Bensussan A, Cease KB et al. Antigens peptides recognised by $\mathrm{T}$ lymphocytes from AIDS viral envelope-immune humans. Nature 1988;334:706-8.

12 Walker CM, Steimer KS, Rosenthal KL, Levy JA. Identification of human immunodeficiency virus (HIV) envelope type-specific T helper cells in an HIV-infected individual. J Clin Invest 1988;82:2172-5.

13 Torseth JW, Berman PV, Merigan TC. Recombinant HIV structural proteins detect specific cellular immunity in vitro in infected individuals. AIDS Res Hum Retrovirus 1988;4:23-30.

14 Ahearne PM, Matthews TJ, Lyerry HK, White GC, Bolognesi D, Weinhold KJ. Cellular immune response to viral peptides in patients exposed to HIV. AIDS Res Hum Retrovirus 1988;4:259-67.

15 Clerici M, Stock NJ, Zajac RA et al. Interleukin-2 production used to detect antigenic peptide recognition by T-helper lymphocytes from asymptomatic HIV-seropositive individuals. Nature 1989;339:383-5.

16 Schrier RD, Gnann JW, Landes R et al. T-cell recognition of HIV synthetic peptides in a natural infection. J Immunol 1989;142:1166-76.

17 Mathiesen T, Broliden PA, Rosen J, Wahren B. Mapping of IgG subclass and T-cell epitopes on HIV proteins by synthetic peptides. Immunology 1989;67:453-9.

18 Wahren B, Rosen J, Sandstrom E, Mathiesen T, Modrow S, Wigzell $\mathrm{H}$. HIV-1 peptides induce a proliferative response in lymphocytes from infected persons. AIDS 1989;4:448-50.

19 Krowka J, Stites D, Debs R et al. Lymphocyte proliferative responses to soluble and liposome-conjugated envelope peptides of HIV-1. J Immunol 1990;144:2535-40.

20 Berzofsky JA, Pendleton CD, Clerici M et al. Construction of peptides encompassing multideterminant clusters of human immunodeficiency virus envelope to induce in vitro $\mathrm{T}$ cell responses in mice and humans of multiple MHC types. J Clin Invest 1991;88:876-84.
21 Manca F, Habeshaw J, Dalgleish A. The naive repertoire of human T helper cells specific for gp 120, the envelope glycoprotein of HIV. J Immunol 1991;146:1964-71.

22 Manca F, Walker L, Newell A, Celada F, Habeshaw JA, Dalgleish AG. Inhibitory activity of HIV envelope gp120 dominates over its antigenicity for human T cells. Clin Exp Immunol 1992;88:17-22.

23 Moore R, Fox BS. Immunization of mice with human immunodeficiency virus glycoprotein gp160 peptide 315-329 induces both class I- and class II-restricted T cells: not all T cells can respond to whole molecule stimulation. AIDS Res Hum Retrovirus 1993;9:51-9.

24 Knight SC, Macatonia SE. Effect of HIV on antigen presentation by dendritic cells and macrophages. Res Virol 1991;142:123-8.

25 Meyaard L, Schuitmaker H, Miedema F. T-cell dysfunction in HIV infection: anergy due to defective antigen-presenting cell function? Immunol Today 1993;14:161-4.

26 Jones WC, Barnard AL, Slade A, Mills KHG. Heterogeneity in the recognition of the simian immunodeficiency virus envelope glycoprotein by $\mathrm{CD}^{+}+\mathrm{T}$ cell clones from immunized macaques. $\mathrm{J}$ Immunol 1992;149:3120-6.

27 Berkower I, Buckenmeyer GK, Berzofsky JA. Molecular mapping of a histocompatibility-restricted immunodominant $\mathrm{T}$ cell epitope with synthetic and natural peptides: implication for $\mathrm{T}$ cell antigen structure. J Immunol 1986;136:2498-503.

28 Cease K, Margalit HM, Cornette JL et al. Helper T-cell antigenic site identification in the acquired immunodeficiency syndrome virus gp120 envelope protein and induction of immunity in mice to the native protein using a 16-residue synthetic peptide. Proc Natl Acad Sci USA 1987;84:4249-53.

29 Delisi C, Berzofsky JA. T cell antigenic sites tend to be amphipatic structures. Proc Natl Acad Sci USA 1985;82:7048-52.

30 Takahashi H, Cohen J, Hosmalin A et al. An immunodominant epitope of the human immunodeficiency virus envelope glycoprotein gp 160 recognized by class I major histocompatibility complex molecule-restricted murine cytotoxic T lymphocytes. Proc Natl Acad Sci USA 1988;85:3105-9.

31 Clerici M, Stocks NI, Zajac RA. Detection of three distinct patterns of $\mathrm{T}$ helper cell dysfunction in asymptomatic, human immunodeficiency virus-seropositive patients: independence of $\mathrm{CD}^{+}{ }^{+}$cell numbers and clinical staging. J Clin Invest 1989;84:1892-9.

32 Lucey DR, Melcher JP, Hendrix CW. Human immunodeficiency virus infection in the US Air Force. Seroconversions, clinical staging and assessment of a T-helper cell functional assay to predict change in CD4 + T-cell counts. J Infect Dis 1991;164:631-7.

33 Miedema F, Petit AJC, Terpstra FG et al. Immunological abnormalities in human immunodeficiency virus (HIV)-infected asymptomatic homosexual men. HIV affects the immune system before $\mathrm{CD}^{+} \mathrm{T}$ helper cell depletion occurs. J Clin Invest 1988;82:1908-14.

34 Bentin J, Tsoukas C, McCutchan JA, Spector SE, Richman DD, Vaghan JH. Impairment in T-lymphocyte responses during early infection with the human immunodeficency virus. J Clin Immunol 1989;9:159-68.

35 Shearer GM, Clerici M. Early T-helper defects in HIV infection. AIDS 1991;5:245-53.

Received 11 November 1993

Accepted 24 November 1993 
This document is a scanned copy of a printed document. No warranty is given about the accuracy of the copy. Users should refer to the original published version of the material. 